\title{
COMMENTARY
}

\section{Awarded innovative and educational good practices against chronic pain across Europe}

\author{
Mariano Votta $^{1^{*}}$ Daniela Quaggia $^{1}$ Gianluca Bruzzese $^{1}$ Maira Cardillo $^{1}$ \\ ${ }^{1}$ Active Citizenship Network, c/o Cittadinazattiva APS, Via Cereate 6, 00183 Rome, Italy
}

\section{Check for updates}

Correspondence to: Mariano Votta, Active Citizenship Network, c/o Cittadinazattiva APS, Via Cereate 6, 00183 Rome, Italy;

E-mail: m.votta@cittadinanzattiva.it

Received: July 13, 2021;

Accepted: August 3, 2021;

Published: August 4, 2021.

Citation: Votta M, Quaggia D, Bruzzese G, et al. Awarded innovative and educational good practices against chronic pain across Europe. Adv Health Behav, 2021, 4(1): 171-176.

https://doi.org/10.25082/AHB.2021.01.003

Copyright: (c) 2021 Mariano Votta et al. This is an open access article distributed under the terms of the Creative Commons Attribution License, which permits unrestricted use, distribution, and reproduction in any medium, provided the original author and source are credited.

\begin{abstract}
In continuation with the second edition [1] of the research project "European Civic Prize on Chronic Pain - Collecting Good Practices", the third edition of the initiative led by Active Citizenship Network, whose term has spanned from 2020-2021, has recently selected several good practices in the fight against chronic pain in the European Union. This year's edition of the Prize has been extremely significant, as it has taken place in the midst of the Covid-19 pandemic, and a diverse approach has been taken in the collection and implementation of good practices. The project has included practices stemming from healthcare professionals, institutions, civic and patient organizations, and other advocative entities for patients in Europe [2]. This article will focus on two of the winning good practices that have been selected by the Jury of experts and will examine initiatives related to Professional Education and Innovation.
\end{abstract}

Keywords: chronic pain, good practices, European Union, education, innovation, patients' rights, civic participation, Patients' Advocacy Groups (PAGs)

\section{Introduction}

Chronic pain and the fight against its repercussions is an issue that has been made relevant not only at the local and national level in recent times, but in European terms as well. Chronic pain can have both physical and psychological effects on patients who deal with it daily, which only makes the need to find practices that reduce or eliminate pain completely as essential. This is why the Italian organization Cittadinanzattiva [3], through its European branch Active Citizenship Network (ACN) [4], has initiated the project "European Civic Prize on Chronic Pain - Collecting Good Practices", which has now reached the conclusion of its III edition. The aim is to highlight the existing good practices in several European countries in terms of struggle against pain and demonstrate how they can serve as a model to healthcare professionals, institutions, healthcare providers, university students, patients' advocacy groups (PAGs), and civic organizations across Europe that wish to improve treatment for patients that suffer from chronic pain. This article will illustrate the following two good practices [5]: one from the "Escola Superior de Saúde Jean Piaget Vila Nova de Gaia" of Porto, Portugal that deals with musculoskeletal pain and professional education regarding this type of pain's characteristics; and another one from the Institute of Biological Chemistry - University of Vienna (Austria) that brings in innovative pain treatments against chronic pain that derive from a peculiar, yet interesting source: animal venom.

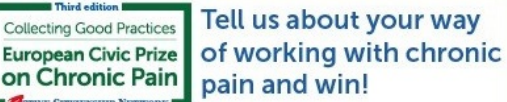

Figure 1 Communication material produced in occasion of the III Edition of the "European Civic Prize on Chronic Pain - Collecting Good Practices"

\section{Best practices}

The aim of this section is to provide details for two best practices awarded by the selective committee, a Jury panel composed by independent experts coming from entities devoted to the topic. 


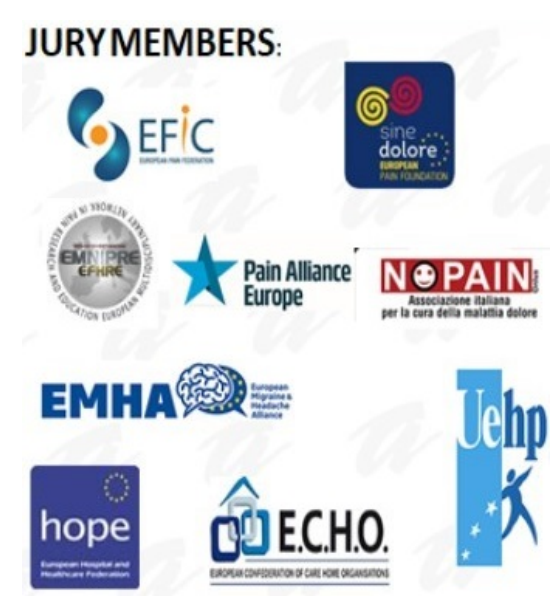

Figure 2 The Jury Members of the III Edition of the "European Civic Prize on Chronic Pain Collecting Good Practices" came from 9 organizations, apart from Active Citizenship Network

\subsection{Criteria used to select the good practices}

In line with the long-term policy of Cittadinanzattiva on good practices [6], and in order to be considered as a Good Practice, the identified initiatives must be concluded or be ongoing and must meet - as much as possible - all the following criteria:

Reproducibility / Transferability:

(1) What it is? The ability to transfer results to other contexts/settings/countries (overcoming legal and other barriers; developing a communication strategy to disseminate the results; already transferred or shown adaptability).

(2) What it isn't? Cases where the conditions that make the initiative possible are exceptional.

\section{Innovativeness:}

(1) What it is? The capacity of producing new solutions.

(2) What it isn't? The mere application of an existing guideline, regulation, or law. However, an example of a good practice could be where an existing guideline, etc. is applied in a particularly innovative way.

\section{Added Value:}

(1) What it is? The capacity of the identified practice to produce a greater impact on the situation.

(2) What it isn't? The practice doesn't bring any significant change to the situation.

\section{Appropriateness:}

(1) What it is? A practice enabling an efficient and effective management of an issue.

(2) What it isn't? Example: a program of meetings between the mayor of Rome and citizens was implemented at the neighborhood level in order to fill the gap between the city administration and the people. Thousands of people participated in the meetings but each one expressed their individual demands, which were too specific, thus hindering the possibility of answering the population's general demands.

\section{Sustainability:}

(1) What it is? The ability to be maintained in the long-term with sustainable resources (economic support, staff training, sustainable strategy).

(2) What it isn't? There is no support to continue the practice (no sustainable strategy).

\section{Intersectoral collaboration:}

(1) What it is? The ability to foster collaboration among different sectors in the field; coordination of social and health services; partnerships; etc.

(2) What it isn't? There is no multidisciplinary approach supported by appropriate stakeholders.

\section{Participation:}

(1) What it is? The inclusion of stakeholders along the whole process and the ability to foster collaboration to promote the empowerment of the target population.

(2) What it isn't? Evaluation and monitoring of the practice wasn't defined with the target population and families or caregivers and the main stakeholders, there was no empowerment of 
the participants (Example: strengthen their health literacy, ensuring the right skills, knowledge and behavior including stress management and health care).

A Good Practice Submission form has been realized ad hoc in an online version [7].

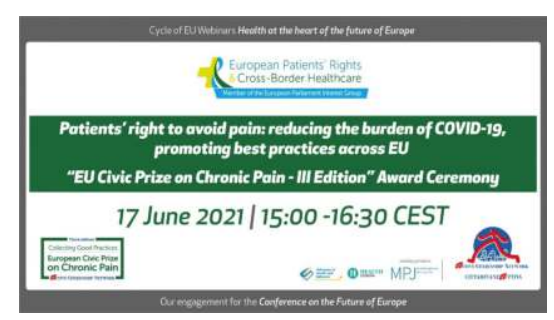

Figure 3 The formal invitation produced in the occasion of the award ceremony realized on June 17, 2021

\subsection{Musculoskeletal pain: knowledge and attitudes of physiother- apy students}

(Escola Superior de Saúde Jean Piaget Vila Nova de Gaia / Jean Piaget School of Health of Vila Nova de Gaia, - Porto, Portugal) [8]. The aim of this study is to assess the knowledge about neuroscience pain and biopsychosocial attitudes in physiotherapy students. The study invites physiotherapy students to participate during 2021 and 2025 in the evaluation of pain within the Portuguese population with the aim to address the fundamental questions of whether more consideration should be provided to pain study in the Portuguese educational curriculum and why a more advanced curriculum could serve as beneficial in the future innovation of therapeutic and other scientific treatments that look at the treatment of pain in general. With this, their main goals are to shift the students' respective opinions and behaviors about pain during the four years and to provide a new sense of importance in both the study and research in musculoskeletal pain. The final objective of the project is to find remedies to those who live with this type of pain in Europe and beyond. A first step of the practice concerns the collection of data in research of musculoskeletal pain on a yearly basis and, in a second step, the data are compared to find potential similarities or abnormalities. Providing students involved in relevant research with the tools necessary for comprehending the effects of musculoskeletal pain could bring about a new importance in pain study and could guarantee new pain services and remedies for those who receive little to no treatment, or who do not have the sufficient healthcare resources in their communities. Active Citizenship Network thanks Sónia Gonçalves-Lopes, Professor of the Physiotherapy Course at Escola Superior de Saúde Jean Piaget Vila Nova de Gaia, for her testimony in occasion of the ceremony of June 17, 2021 [9].

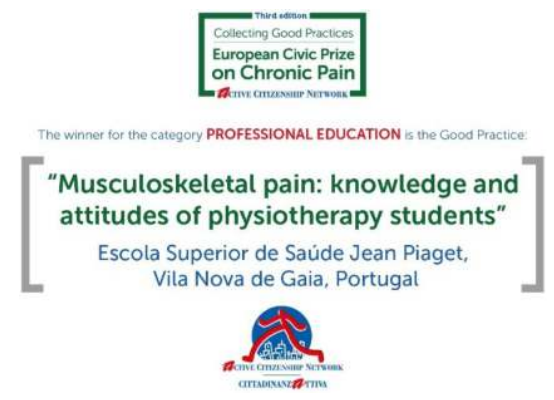

Figure 4 The plaque realized in the occasion of the ceremony of the III Edition of the Prize on June 17, 2021 and given to the Portuguese Jean Piaget School of Health of Vila Nova de Gaia

\subsection{From venomous animals to innovative pain treatments}

(Institute of Biological Chemistry - University of Vienna - Austria) [10]. In terms of new, innovative practices against chronic pain, the mentioned above University's healthcare and biological departments, have provided a potential solution to chronic neuropathic pain using animal venom, primarily that of spiders, cone snails, and scorpions. The practice combines research studies done by analyzing patients' experiences with chronic neuropathic pain and the study of animal venom and its respective impacts in the field of clinical treatments. The practice aims at providing solutions for the percentage of the European population which deals 
with chronic neuropathic pain, which is estimated to be around 7-8\% of the EU's population by the University of Vienna [11]. The Institute has already published relevant findings and research in scholarly journals and other sources of information that demonstrate how the use of animal venom can be more efficient and safer than currently available painkillers in the treatment of chronic neuropathic pain. Improving patients' lives is the ultimate objective of this initiative. Active Citizenship Network thanks Markus Muttenthaler, Associated Professor of the Institute of Biological Chemistry at the University of Vienna, for his testimony in occasion of the ceremony of June 17, 2021 [12].

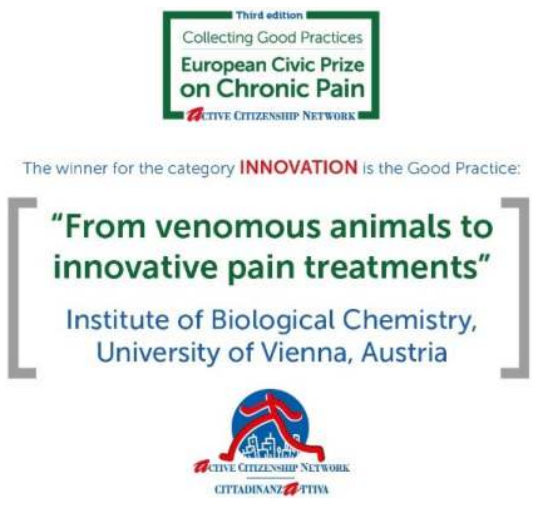

Figure 5 The plaque realized in the occasion of the ceremony of the III Edition of the Prize on June 17, 2021 and given to the Institute of Biological Chemistry of the University of Vienna

\section{Ethic statement}

The authors have worked in full compliance with the Code of Conduct of Cittadinanzattiva APS [13].

\section{Discussion}

These practices highlight diverse, yet effective manners in which the musculoskeletal and neuropathic forms of chronic pain can be tackled.

In particular, the Jury panel has deemed the good practice of the University of Vienna as a "very innovative project with a potential high added value". Indeed, chronic neuropathic pain results from damage to the central or peripheral nervous system due to injury or disease and is a leading cause of disability. Existing painkillers have several limitations, including poor tolerability and addiction concerns; therefore, there is an urgent need to develop better and non-addictive painkillers. Neuropathic pain is transduced via a complex network of ion channels and some of these have been identified as highly promising new targets for painkillers. Intriguingly, peptides from the venoms of spiders, cone snails, and scorpions can selectively and potently block such ion channels. The University of Vienna uses such venom peptides to study pain pathways, validate new pain targets, and develop therapeutic candidates with improved properties compared to currently available painkillers. By combining these research activities with teaching, collaboration with the pharmaceutical industry, and public outreach, the researchers aim to accelerate application-oriented research into neuropathic pain and to bring new innovative solutions to people that suffer from chronic pain.

The Portuguese good practice has also been much appreciated by the Jury panel. Indeed, as widely known, chronic pain is one of the main reasons why people seek physical therapy. Pain is a cerebral natural way of alert to a problem, but chronic pain persists for weeks, months or even years. Regardless the body damage, this condition can be present and have different impacts on people's functionality (e.g.: decreased activity level, absenteeism, financial problems, depression). The Jean Piaget School of Health from Portugal strongly believes that the professionals' attitudes and beliefs about pain can influence their intervention, and therefore it's important to be fully prepared to provide an adequate support. From Portugal comes the message that it is crucial to start with the students, evaluating and improving their knowledge, better prepare them to intervention, and, if necessary, make some changes in the curricula to address new strategies.

We believe that good practices are a small, but significant indicator of the health status of our healthcare systems, which have long been under pressure between the need for economic 


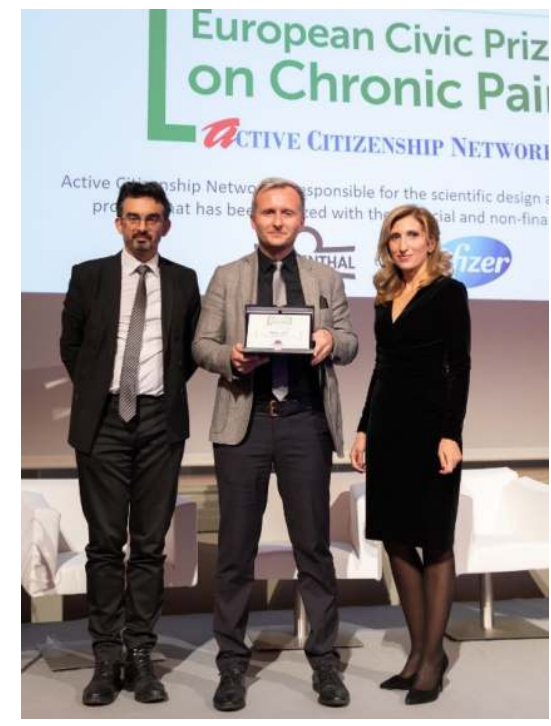

Figure 6 Prize giving by Alba Malara (Scientific Coordinator - European Confederation of care home organization) \& Pascal Garel (Secretary-General - European Hospital and health care federation), members of the Jury panel. Winner called at the stage to withdraw the prize for the category "clinical practices": Janosch Priebe Senior research fellow, Center of Interdisciplinary Pain Medicine, Technical University of Munich, Germany. European Civic Prize on Chronic Pain, Second Edition (Award Ceremony within SIP Symposium, Brussels, 6 November 2019). (C) Isabelle Pateer

sustainability and the high expectations of the population. Health protection as a common good should be the common denominator that unites the many stakeholders involved in the health sector, especially in the fight against every form of inequality in access to therapies. The area of pain is no exception: reducing inequalities to allow a better quality of life for people suffering from chronic pain is the challenge we are facing and will continue to do so in the coming years. As the Italian Minister of Health Beatrice Lorenzin has underlined during the meeting of the European Union Health Council in 2014: "It is of fundamental importance to guarantee access to pain therapy (...) to reduce the existing inequalities in healthcare between regions and Member States of the European Union in the area of equal rights to health" [14]. We are working towards the achievement of this goal through our initiative started in 2015 "European Civic Prize on Chronic Pain - Collecting Good Practices," which has now reached the conclusion of its III edition. This unique project aims at publicizing existing innovative, exciting, and proactive practices in pain management services and pain education in Europe in order to provide solutions and support to people suffering from chronic pain.

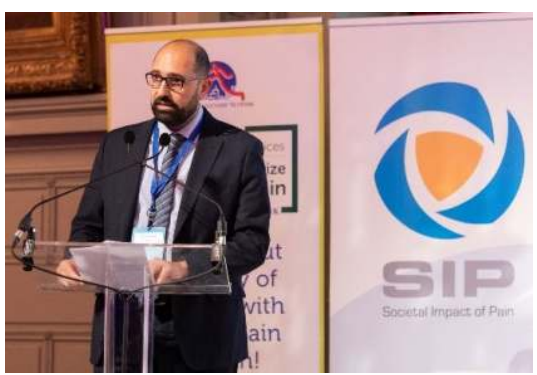

Figure 7 Mariano Votta, Director Active Citizenship Network during the opening remarks of the European Civic Prize on Chronic Pain, Second Edition (Award Ceremony within SIP Symposium, Brussels, 6 November 2019). (C) Isabelle Pateer

\section{Acknowledgements}

Active Citizenship Network is responsible for the scientific design and contents of the "European Civic Prize on Chronic Pain Collecting Good Practices - III edition 2020-2021" EU Project, that has been realized with the financial and non-financial support of Pfizer. Active 
Citizenship Network wishes to acknowledge all the members of the jury panel: Alba Malara, European Confederation of Care Home Organisations (ECHO); Gemma Fernandez, Sine Dolore European Pain Foundation; Pascal Garel, European Hospital and Healthcare Federation (HOPE); Ilaria Giannico, European Union of Private Hospitals (UEHP); Joop van Griesven, Pain Alliance Europe (PAE); Rita Amabile, No Pain Onlus; Jordi Moya, European Multidisciplinary Network in Pain Research and Education; Kalina Tyminski, European Headache and Migraine Alliance (EHMA); and Brona Fullen, European Pain Federation (EFIC).

\section{References}

[1] European Civic Prize on Chronic Pain Collecting Good Practices Second Edition 2018-2019. http://www.activecitizenship.net/patients-rights/projects/261-european-civic-prize-on-chronic-pai n-collecting-good-practices-second-edition-2018-2019.html

[2] Guidelines, "European Civic Prize on Chronic Pain" Collecting Good Practices III Edition. http://www.activecitizenship.net/files/Guidelines_III_Edition_European_Civic_Prize_on_Chronic_P ain_30_Aprile.pdf

[3] Cittadinanzattiva APS, Italian civic organization founded in Italy in 1978 and active at the EU level since 2001. http://www.cittadinanzattiva.it

[4] Active Citizenship Network, EU and international branch of the Italian NGO Cittadinanzattiva. http://activecitizenship.net

[5] European Civic Prize on Chronic Pain Collecting Good Practices Third Edition 2020-2021. http://www.activecitizenship.net/patients-rights/projects/332-european-civic-prize-on-chronic-pai n-collecting-good-practices-iii-edition-2020-2021.html

[6] Good Practice: The Policy of Cittadinanzattiva. http://www.cittadinanzattiva.it/approfondimenti/attivismo-civico/cittadinanza-dimpresa/4972-goo d-practice-the-policy-of-cittadinanzattiva.html

[7] ACN - Good Practices Database (Submission Forms). http://www.activecitizenship.net/bp/2020/form/new.php

[8] Escola Superior de Saúde: Instituto Piaget. Official website. https://ipiaget.org/escola-superior-de-saude-vila-nova-de-gaia/1520963385220-55b53321-14d4

[9] The testimony of Sónia Gonçalves-Lopes, Professor of the Physiotherapy Course at Escola Superior de Saúde Jean Piaget Vila Nova de Gaia, in occasion of the ceremony of June 17, 2021. http://www.youtube.com/watch?v=TfXTpSXZbqk\&list=PLTY7bwIIOhM2vORoBO6fL69jZ6ixJQ 9Uy\&index $=4$

[10] Markus Muttenthaler: Neuropeptide Research Lab: Queensland: Vienna. neuropeptide lab. Official website. http://www.neuropeptidelab.com

[11] Muttenthaler M and Inserra M. (4 November 2019). From cone snail venom to pain relief. medienportal.univie.ac.at

https://medienportal.univie.ac.at/presse/aktuelle-pressemeldungen/detailansicht/artikel/from-conesnail-venom-to-pain-relief/

[12] The testimony of Markus Muttenthaler, Associated Professor of the Institute of Biological Chemistry at the University of Vienna, in occasion of the ceremony of June 17, 2021. http://www.youtube.com/watch?v=nyR5jIVTqvo\&list=PLTY7bwII0hM2vORoBO6fL69jZ6ixJQ 9Uy\&index $=3$

[13] Cittadinanzattiva APS, "Code of Conduct." http://www.cittadinanzattiva.it/files/corporate/istituzionale/documenti_identita/codice_condotta_ca. pdf

[14] Beatrice Lorenzin, IT Minister of Health, in occasion of the Informal Council of EU Health Ministers, 2014.

http://www.activecitizenship.net/files/patients_rights/Speech_Lorenzin_Handout_Delegate_packs_a t_SIP_ENversion.pdf 